\title{
Contributions of Consumer-perceived Creativity and Beauty to Willingness-to-pay for Design Products
}

\author{
Christensen, Bo Thomas; Kristensen, Tore; Reber, Rolf
}

\author{
Document Version \\ Accepted author manuscript \\ Published in: \\ International Journal of Design Creativity and Innovation
}

DOI:

10.1080/21650349.2014.981216

Publication date:

2015

License

Unspecified

Citation for published version (APA):

Christensen, B. T., Kristensen, T., \& Reber, R. (2015). Contributions of Consumer-perceived Creativity and Beauty to Willingness-to-pay for Design Products. International Journal of Design Creativity and Innovation, 3(34), 164-176. https://doi.org/10.1080/21650349.2014.981216

Link to publication in CBS Research Portal

\section{General rights}

Copyright and moral rights for the publications made accessible in the public portal are retained by the authors and/or other copyright owners and it is a condition of accessing publications that users recognise and abide by the legal requirements associated with these rights.

\section{Take down policy}

If you believe that this document breaches copyright please contact us (research.lib@cbs.dk) providing details, and we will remove access to the work immediately and investigate your claim. 


\title{
Contributions of Consumer-perceived Creativity and Beauty to Willingness-to-pay for Design Products
}

\section{Bo Thomas Christensen, Tore Kristensen, and Rolf Reber}

\author{
Journal article (Post print version)
}

Cite: Contributions of Consumer-perceived Creativity and Beauty to Willingness-to-pay for Design Products. / Christensen, Bo Thomas; Kristensen, Tore; Reber, Rolf. In: International Journal of Design Creativity and Innovation, Vol. 3, No. 3-4, 2015, p. 164-176.

This is an Accepted Manuscript of an article published by Taylor \& Francis in International Journal of Design Creativity and Innovation on 14 November २०14, available online:

http://www.tandfonline.com/10.1080/21650349.2014.981216

Uploaded to Research@CBS: December २016

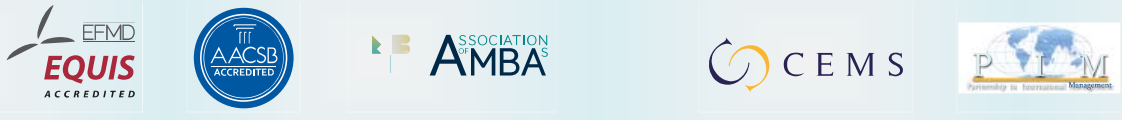


Contributions of perceived creativity and beauty to willingness-to-pay for design products.

\begin{abstract}
Consumer perception of creativity in design products equivalent in function was measured using global single-item ratings of creativity. The measure was found to have a high level of agreement between raters and have discriminant validity to another aesthetic construct, that of beauty. In two experiments using designer lamps and wrist watches as stimuli, the present study shows how creativity and beauty both positively influence consumer willingness-to-pay for the designed product, but each explains different parts of the variance. The results show that it is essential to develop separate models of creativity and beauty evaluations in consumer psychology, in that they seem to be distinct factors, explaining different parts of the variance in their consequences on willingness to pay.
\end{abstract}

Keywords: Consumer perception, perceived creativity, perceived beauty, willingness to pay, product aesthetics. 
Contributions of perceived creativity and beauty to willingness-to-pay for design products.

The aesthetic qualities of consumer products are increasingly becoming important factors in consumer behavior and preference formation. The design of products (such as perceived quality, and aesthetics) has been shown to be important in determining the success of a new product (Bruce \& Whitehead, 1988). Consumer products are not only differentiated by price and functionality, but equally so by experiential qualities (Holbrook \& Hirschman, 1982), such as emotional appeal (Moore \& Harris, 1996), humor (Eisend, 2009), and aesthetic qualities (Holbrook, 1980). The present study examines consumer perceptions of qualities of designed objects, and the consequence thereof on consumer valuation.

Consumer judgments of aesthetic value in products may take several forms, two of the important ones being beauty, which is perhaps the generic sort of aesthetic excellence (Zangwill, 2003) and creativity, which is a hallmark of art (Alpeson, 2003), advertising (Sasser \& Koslow, 2008; Smith, Chen, \& Yang, 2008), and product design (Goldschmidt \& Tatsa, 2005; Yusuf, 2009). Both concepts are honorific and carry with them notions of positive value in making product judgments. Furthermore, scholars have argued that consumer judgments of both product creativity and beauty are of importance in consumer psychology because they influence preference formation and consumer choice (Besemer \& Treffinger, 1981). Dahlen, Törn, and Rosengren (2008) used similar approaches to that used here and found that consumer perceived creativity of advertising led to the perception of increased brand quality and increased brand interest. Despite some past research conducted on consumer perception of creativity (Besemer \& O’Quin, 1999; Besemer, 1998; Bell, 1992), it is not clear whether consumers’ perceived estimates of beauty and creativity influence consumer behavior in the same, or alternative, ways, and whether these perceptions are affected in the same way by antecedent factors. 
Consumer-perceived creativity should not be confused with practitioner perceived creativity (that is, practitioner estimates of creativity in the given product domain), in that the two have been found to differ significantly in advertising (West, Kover \& Caruana, 2008). In this article, we focus solely on the perception of creativity in products in consumption contexts, and the word 'creativity' will thus solely be used in reference to consumer-perceived levels of creativity in consumer products.

We argue that it may be possible to evaluate creativity in products that differ mainly in how they are experienced (where functional value cannot be discerned or is unimportant), such as conspicuously displayed art objects. It may be possible to judge creativity as an experiential value along with other aesthetic constructs, such as beauty. This makes for a creativity construct that is based primarily on the experiential qualities of perceiving the products, rather than on the underlying benefits, usability, or relative advantage of some products over others. Such types of evaluation may be found in products where the product design or the experience of perceiving is pertinent to the evaluation of the object (e.g., advertising, art, design, architecture, theatre, movies etc.). In many of these product categories, creativity and beauty can be considered determining factors for consumers, whereby it is of utmost importance for brands to differentiate themselves from their competitors on these factors (Keller, 2008).

One approach to the evaluation of creativity in products that can be identified in the literature is the use of multiple-item scale measurements of key components in the creativity construct, as carried out by laymen and/or consumers (Horn \& Salvendy, 2006; O’Quin \& Besemer, 1989; 2006; 2011; Besemer \& O’Quin, 1999). Multi-item creativity scales assume that creativity is a construct formed of a number of components. Horn \& Salvendy (2006) suggests six components in judging creativity in design: novelty (the newness of the product), resolution (the ability of the product to resolve a problem), emotion (the pleasure or arousal induced by the product), centrality (ability to match consumer needs), importance (importance to consumer needs) and desire (how critical or desirable 
the product is). O’Quin \& Besemer (2006; 1989) proposes three components: novelty, resolution and style (previously termed 'elaboration and synthesis'). Separating creativity into subcomponents has, however, been criticized by Amabile (1982), who argued that definitions of creativity do not include conceptualizations that are readily translated into useful assessment criteria, let alone ultimate criteria or fixed components. Indeed, Amabile argued that it is impossible to specify such ultimate criteria, given the reliance in creativity judgments on a social and changing context. The components of creativity may vary by domain; and it is unclear how to weigh the components in the aggregate measure. Indeed, while most scales of creativity measurements rely on additive subcomponents, research has shown that the components are by no means equally weighed in subjective measures of creativity, with, for example, the originality dimension frequently proving much more important than appropriateness (Caroff \& Besancon, 2008; Runco \& Charles, 1993; Kudrowitz \& Wallace, 2012; Christiaans, 2002). For the present purposes, we are interested in aesthetic judgments of creativity (as in the judgment of the experiential value of an advert or design), rather than functional or use value as is typically evaluated in the 'appropriateness' part of creativity, and therefore it seems valid to avoid explicitly using a 'usefulness' or 'appropriateness' component in the measure of creativity.

Given our interest in measuring consumer-perceived creativity and consumer-perceived beauty in consumer products we utilized single-item measures, following past research on both creativity (Dahlen, Törn, \& Rosengren, 2008), and beauty (Hekkert, Snelders, Wieringen, 2003; Hassenzahl, 2004). In this way, consumer's own global understanding of creativity and beauty in products is utilized, and we avoid drawing on - for our purposes - problematic assumptions of which components (e.g., originality, usefulness) to include in the measure, and how to weigh them. Past similar research approaches have revealed remarkably stable beauty judgments across raters (Hasenzahl, 2004; Hekkert et al., 2003). 


\section{The relationship between beauty and creativity}

From a consumer perception viewpoint, it can be hypothesized that an antagonism exists between creativity and beauty. Novelty is an integral part of creativity (Mayer, 1999). Indeed, in making creativity evaluations, people tend to make categorical comparisons, for example by noting original or unusual features. Therefore, creativity has been closely linked to judgments of novelty: The more novel, the more creative. Beauty, on the other hand, has been linked with the opposite end of the typicality-novelty dimension. Theories of perceptual fluency hold that typicality increases fluency, which is the ease with which input information flows through the cognitive system. Perceptual fluency, in turn, has been shown to be affectively positive (Reber, Winkielman, \& Schwarz, 1998; Winkielman \& Cacioppo, 2001; see Reber, Schwarz, \& Winkielman, 2004 for a review). Studies in consumer research have documented that variables that result in perceptual fluency, such as prototypicality and unity (Veryzer \& Hutchinson, 1998) or familiarity (Janiszewski, 1993) influence aesthetic responses or affect. Therefore, beauty judgments have been closely linked to judgments of typicality: The more typical or familiar, the more beautiful. Constructs relating to novelty-typicality have the potential to inform us whether creativity and beauty indeed in some cases may be distinctly influenced by antecedent factors, and maybe even (in the case of novelty-typicality), that they may be driven in opposite directions. For example, Purcell (1984) and Christiaans (2002) suggested that product prototypicality would indeed lead to differences in beauty and creativity evaluations. Cho and Schwarz (2006) found in their study that when participants low in Need for Cognition made beauty judgments, they liked products more when the product description was easy to read, but the same participants subsequently judged the same product as being less innovative. However, if participants had first to indicate whether a product was innovative, Cho and Schwarz found a carry-over effect in that participants judged products whose description was difficult to read as being both innovative and beautiful. Finally, in 
an important study, Hekkert, Snelders \& Wieringen (2003) argued that aesthetic preference for consumer products is the result of a process in which typicality and novelty are jointly taken into account, and where both factors are equally important as explanatory factors. However, typicality and novelty suppress each other's effects (given they are highly negatively correlated), and therefore the impact of novelty [typicality] on aesthetic preference may only be evident when suppressing the effect of typicality [novelty]. Consequently, in their results, Hekkert et al (2003) found no evidence of a direct effect of novelty on preference -an effect only became evident upon removal of the shared variance with typicality. Blijlevens, Mugge, Carbon \& Schoomans (2012), however, found direct effects of typicality on preference, without controlling for novelty. While Hekkert et al. (2003) argued strongly for the potential positive effect of typicality on aesthetic preference (as also supported by fluency theory), it can be argued that creativity judgments should display a different pattern of results. While creativity judgments may well also be influenced by both novelty and typicality (in addition to other factors for example relating to valuation), the impact of typicality on creativity should in this case be negative given that creativity may arise both as a consequence of novel features, and as a consequence of atypical category membership. The resulting pattern to be expected would be increased creativity evaluations upon lower typicality scores.

Several recent empirical studies that have examined the link between perceptions of beauty, creativity and other factors by using factor analytic studies, have consistently found that beauty and creativity load on different factors. Two studies in art perception have conducted factor analyses on beauty and creativity items. Kozbelt (2004) studied originality and technical skill as components of artistic creativity (judging 72 drawings), and found that whereas both creativity and beauty items loaded onto the product quality dimension in art, the creativity and beauty items loaded on different factors in the factor analytic study. Even though Kozbelt had hypothesized that beauty would be on 
the originality factor, in fact beauty did not load on the same dimension as items such as 'original, creative, imaginative, surprising, possibility of interpretation’, etc. Hagtvedt, Hagtvedt \& Patrick (2008) used five figurative paintings as stimuli, and found in the perceived attributes factor loadings that creativity and aesthetic appeal (e.g., beauty) appeared to be two different factors, incidentally with the two items of 'beauty' and 'creativity' having the highest factor loadings in their respective factors. These studies present empirical evidence that creativity and beauty are two different factors, in art evaluation. However, the comparison between creativity and beauty has not been directly made in the consumer products category. In the present study we tried to test whether creativity and beauty correlate in consumer products when comparing averaged by-item responses for consumer ratings. Much past research has relied on multiple individual responses to a restricted range of products (leading to examinations of naïve theories of the relation of the concepts). Our approach instead focused on by-item correlations for a large range of products leading to examinations of how product characteristics on average influence judgments like creativity and beauty (Hasselzahl, 2008), and how they in turn influence consumers' willingness to pay for the product. The choice of by-item correlations between distinct groups of consumers was made in order to more firmly attest that consumer-perceived creativity can be used to make predictions from one group making creativity ratings, to the perceived economic value of the same object in another group. At the same time, however, this choice makes it less straightforward to conclude on how the concepts of interest here relate to each other in the individual consumer's mind.

\section{Creativity and beauty predicts consumer behavior}

Whereas both creativity and beauty have been argued to be predictors of consumer behavior, it is for different theoretical reasons. Although consumer psychology models would hold that both creativity judgments and beauty judgments should predict consumers' willingness to pay for the product, they should not explain the same variance. Consumers are not always after easy processing 
- sometimes they tend to prefer novel or original instances (Bianchi, 1998; Simonson \& Nowles, 2000; Hekkert et al., 2008).

The marketing literature on innovativeness has tended to focus on how different consumers have a preference for adopting products early in the product life cycle, whereas others tend to postpone adoption, or not adopt at all (e.g., Rogers, 1976). In directing the argument towards the perception of innovativeness or originality in products, some authors have argued that consumers hold a preference for novelty in consumer products (see e.g., Hirschman, 1980). In three studies of consumer products (such as chairs and lamps), Horn \& Salvendy (2009) showed that at least some of the dimensions of product creativity successfully predicted consumer attitudes (consumer satisfaction, and their willingness to purchase). In such models, product differentiation and novelty of product features are at the forefront, in comparison to earlier products, and to what competitors have to offer. Categorical comparisons of the typicality of products may possess a marketing advantage, in that consumers tend to prefer products with original and unique features.

Similar to perceived creativity, perceived beauty has been linked to increases in valuation in consumer behavior. Bloch, Brunel \& Arnold (2003) showed consumers two different pictures of toasters equal in functionality, but differing in beauty. Consumers rated their willingness to pay for the toasters, revealing that participants were willing to pay about 55\% more for a beautiful toaster. Similar results have been obtained by Hasselzahl (unpublished study, quoted in Hasselzahl, 2008) with mobile phones. The series of experiments conducted by Bloch et al. (2003) further suggested that the beauty effect on valuation was moderated by individual differences in what he called 'centrality of visual product aesthetics' (CVPA). CVPA moderated both the overall evaluation, the purchase intention, and the willingness to pay in the above mentioned toaster study.

Instead of assessing interindividual differences in order to determine whose willingness to pay is based on either perceived beauty or creativity, we address the question whether perceived beauty 
and creativity simultaneously affect willingness to pay. It is possible that consumer perceptions of creativity and beauty affect willingness to pay in the same way, or alternative ways. As reviewed above, evidence exist that both creativity and beauty judgments would predict consumer’s willingness to pay for the product. However, to our knowledge, it has not yet been tested whether creativity and beauty predict the same or differing parts of the variance. It is possible that creativity and beauty would predict the same consumer behavior variance, if for example preference formation for consumer products was influenced in the same way by creativity and beauty judgments; this would be the case if there was a strong correlation between creativity and beauty. Alternatively, if creativity and beauty judgments drew on distinct theoretical models of evaluation, and since creativity and beauty judgments have been shown empirically to load on distinct factors, they may explain different parts of the willingness to pay variance. Based on this alternative rationale, creativity and beauty judgments would both be predictors of consumers' willingness to pay for consumer products, and would predict different parts of the variance. Finally, it is also possible that only when a consumer product is perceived to be both creative and beautiful will an effect of consumer behavior be evident.

\section{The present study}

The present series of experiments tested whether consumer perceptions of creativity in products equivalent in function 1) have a high level of agreement among consumers; 2) has discriminate validity to beauty; 3) predict consumer willingness to pay for the product. To anticipate the findings, the present set of experiments provides compelling evidence that in the domain of consumer products consumers clearly distinguish between creativity and beauty; their evaluations of creativity and beauty explain different parts of the variance in their willingness to pay. In the present experimental setup, it was assumed that participants would constitute potential consumers, when placed in a consumption context and asked to make product ratings related to consumption. 
As in many experimental setups it is debatable whether the participants would indeed constitute consumers for these particular product categories in real life (e.g., the use of wristwatches in student populations is declining due to the prevalence of watch functions in cell phones). However, although the present sampling may not be representative for the population of consumers, we have no a priori reason to assume that the current sampling biases the specific constructs measured, or their hypothesized relations.

\section{Experiment 1}

\section{Method}

\section{Subjects}

Ninety-three business undergraduates from Copenhagen Business School (34 female; mean age 23) were asked to judge pictures of designer lamps.

\section{Materials}

In a pre-study, 10 subjects who did not participate in the main study judged pictures of 100 designer hanging lamps for complexity. The 100 pictures of lamps were downloaded from lamp traders on the internet (e.g., http://www.luksuslamper.dk; www.lampeland.dk; all retrieved in February 2009) to represent a mixture of brands and styles, see figure one for example stimuli. The pictures were converted into black and white to accommodate that some of the sample images were only available in B/W while others were in color. Based on the responses, a total of 36 lamp images were selected for the experiment for representing variety in lamp styles, variation in complexity levels, and for being in the same price range.

\section{Procedure}

Pictures were presented for 2 s on a 17” computer monitor using E-prime ${ }^{\circledR}$ presentation software (Schneider, Eschman, \& Zuccolotto, 2002). Prior to judging the experimental pictures the participants saw two test-images to familiarize them with the task. Each picture was preceded by a 
fixation point presented for $500 \mathrm{~ms}$. The order of presentation of the 36 lamp pictures was randomized. Participants rated the same series of 36 pictures of lamps three times for a total of 108 judgments. Thirty-two participants first made (B) beauty judgments ('how beautiful is the lamp') on an on-screen $10 \mathrm{~cm}$ long visual analogue scale ranging from 0 , 'ugly' to 100 , 'beautiful', followed by (W) willingness-to-pay judgments ('how much would you be willing to pay for this lamp'; ranging from USD 0 to USD $1100^{\mathrm{i}}$ ), followed by (C) creativity judgments ('how creative is the lamp'; ranging from 0, 'uncreative' to 100 'creative'). For the other subjects, the ordering of judgments was reversed, with 31 subjects judging CWB, 15 judging WCB and 15 judging WBC. The three different instructions allowed us to test interrater agreement between groups with different instruction orderings

Results and discussion

The lamp pictures had the following by-item means: creativity $(M=57.2, S D=12.2)$, beauty $(M=45.9, S D=12.1)$, willingness to pay $(M=$ USD 300.4, $S D=$ USD 59.9, ranging from USD 191.4 to USD 422.7).

Agreement across participants was computed using Intraclass correlation coefficients; twoway, random for consistency using average measures; ICC $(2, k)$ (Shrout \& Fleiss, 1979). Agreement across raters was substantial (as per the benchmarks suggested by Shrout, 1998) on both creativity and beauty, and moderate agreement was shown for willingness to pay: Creativity (rated first) $\operatorname{ICC}(2,31)=.917$; beauty (rated first) $\operatorname{ICC}(2,32)=.883$; Willingness to pay (rated first) ICC $(2,30)=.708$. The correlation coefficient expressing inter-rater agreement between the group that rated creativity first, and the group that rated creativity subsequent to beauty $(r(36)=.85, p<.001)$ and creativity subsequent to willingness to pay $(r(36)=.91, p<.001)$ were satisfactory. See Table 2 for ICC and inter-rater agreement correlations between groups for all measures. Note that inter-rater 
agreement was higher for perceived creativity than for beauty or willingness to pay. The by-item correlation between creativity and beauty was small and negative, $r(36)=-.35, p<.04$.

Table 1 about here

Table 1 illustrates instruction ordering effects (small to medium correlations for beauty and willingness to pay between instruction orderings, particularly the latter illustrating a large ordering effect). To substantiate this, repeated measures GLM were used to examine whether instruction ordering interacted with object complexity. Significant interaction effects between instruction ordering and complexity was found for all three measures, but with the largest effect for willingness to pay (creativity: $F(4,178)=3.48, p<.01$; beauty: $F(4,180)=5.74, p<.001$; WtP: $F(4,182)=12.00$, $p<.001$ ). As a consequence of this ordering effect, only the first rating by each subject was used in the below regression analyses.

To test whether creativity and beauty evaluations explained different parts of consumers’ willingness-to-pay for the product, we ran a multiple regression analysis on the by-item averages with willingness-to-pay as the dependent factor, and creativity and beauty evaluations as the independent factors. Regressing willingness-to-pay (rated first) onto creativity (rated first) and beauty (rated first) yielded the following results: Creativity significantly predicted willingness-topay scores, $\beta=.46, t(35)=2.86, p<.01$, as did beauty, $\beta=.42, t(35)=2.62, p<.02$. Creativity and beauty combined explained a significant proportion of variance in willingness-to-pay, adjusted $R^{2}=$ $.21, F(2,35)=5.59, p<.01$. To illustrate the impact of creativity and beauty on willingness-to-pay, we show the ten least beautiful/creative lamps and the most beautiful/creative lamps in terms of how much on average the subjects were willing-to-pay for them (see Table 2). 
Table 2 about here

In order to test whether subjects were inferring either creativity or beauty judgments from a perceptual evaluation of how expensive the lamps looked, we ran a further regression which included the list price of each lamp. Here, again, creativity significantly predicted willingness-topay scores, $\beta=.47, t(35)=2.89, p<.01$, as did beauty, $\beta=.46, t(35)=2.71, p<.02$, while list price failed to contribute to willingness-of-pay, $\beta=.12$, $t(35)=0.77$, NS, ruling out this possible confound. To estimate whether there were interaction effects between creativity and beauty (for example, if creativity and beauty both needed to be high before WtP was affected), a stepwise regression was carried out, with the first step regressing WtP onto beauty and creativity, and a second step adding creativity*beauty. Adding the second step did not increase the adjusted $R^{2}$, indicating that no significant interaction effect was present. Thus, creativity and beauty both predicted willingness-to-pay, but explained different parts of the variance.

The lamp experiment showed that both creativity and beauty independently predicted willingness to pay. In order to try to generalize these findings to other consumer products, we conducted a second experiment using another consumer product category of stimuli: wrist watches. In order to test whether the finding that creativity and beauty predict WtP between consumer groups generalize within ratings in the same consumer group, we asked the same subjects to rate the watches three times.

\section{Experiment 2}

\section{Method}

Subjects 
Forty-eight female business undergraduate students from Copenhagen Business School (mean age 23) were asked to judge pictures of wrist-watches. None of the participants participated in the former study.

\section{Materials}

In a pre-study, ten subjects who did not participate in the main study judged pictures of 60 female wrist watches for complexity. The 60 pictures of watches were downloaded from the JC Penney website (http://www.jcpenney.com; retrieved in February 2009) to represent a mixture of brands and styles. In each picture the brand name and logo (if present) was digitally removed.

Based on the responses, 30 female wrist watches were selected to represent a mixture of watch styles, for being in the same price range and for variation in complexity levels, for a total of 30 watches ${ }^{\text {ii }}$ used in the experiment.

\section{Procedure}

Prior to judging the experimental set of watches, the participants saw three test-images of watches to familiarize them with the task.

In the experiment, 16 participants first made (B) beauty judgments ('how beautiful is the watch'), followed by (W) willingness-to-pay judgments ('how much would you be willing to pay for this watch'; ranging from USD 0 to USD 550), followed by (C) creativity judgments ('how creative is the watch'). For the other subjects, the ordering of judgments was reversed, with 16 subjects judging CWB, 8 judging WCB and 8 judging WBC. Otherwise the procedure was identical to Experiment 1.

Results and discussion

The watch pictures had the following by-item means: creativity $(M=45.2, S D=13.9)$, beauty $(M=37.9, S D=8.2)$, willingness to pay ( $M=$ USD 116.8, $S D=$ USD 30.6, ranging from USD 56.2 to USD 182.1). Agreement across the 48 participants (each rating all measures) was substantial on all 
measures: Creativity ICC $(2,48)=.960$; beauty $\operatorname{ICC}(2,48)=.846$; Willingness to pay ICC $(2,48)=$ .850. The by-item correlation between creativity and beauty evaluations was slightly positive, but insignificantly so, $r(30)=.27(\mathrm{NS})$.

Repeated measures GLM used to examine whether instruction ordering interacted with complexity revealed no significant differences between instruction orderings ( $F$ 's $<1.52)$, therefore all three ratings by each subject were used in the below regression analyses.

Regressing creativity and beauty onto willingness-to-pay yielded the following results: Creativity significantly predicted willingness-to-pay scores, $\beta=.56, t(29)=7.22, p<.001$, as did beauty, $\beta=.60, t(29)=7.81, p<.001$. Creativity and beauty combined explained a significant proportion of variance in willingness-to-pay, adjusted $R^{2}=.84, F(2,29)=76.82, p<.001$. In order to test whether subjects were inferring either creativity or beauty judgments from a perceptual evaluation of how expensive the watches looked, we ran a further regression which included the list price of each watch. Here, again, this possible confound could be ruled out, as creativity significantly predicted willingness-to-pay scores, $\beta=.56, t(29)=7.91, p<.001$, as did beauty, $\beta=$ $.56, t(29)=7.78, p<.001$, and list price $\beta=.17, t(29)=2.46, p<.03$. Creativity, beauty, and list price combined again explained a significant proportion of variance in willingness-to-pay, adjusted $R^{2}=.87, F(2,29)=62.78, p<.001$. Including list price in the analysis did not change the explanatory power of either creativity or beauty, but list price was an independent contributor to willingness to pay. As in study 1, a stepwise regression adding interaction effects between creativity and beauty as a second step did not increase the adjusted $R^{2}$.

\section{General discussion}

The present experiments have demonstrated that it is possible to reach a high level of agreement on consumer perceptions of creativity in products equivalent in function using single-item measures. In both experiments, satisfactory agreement was reached with 31-48 subjects. Furthermore, the group 
average of consumer perceived creativity and beauty had significant effect on willingness-to-pay estimates carried out by another consumer group, evidencing the predictive validity of the measure.

Although both beauty and creativity are honorific aesthetic judgments, consumer perceived creativity and beauty showed clear discriminate validity in the present experiments. In so far as typicality and novelty are approximately equal predictors of creativity (as they appeared to be of beauty in the Hekkert et al. (2003) study), one could as a result expect a near-zero correlation between creativity and beauty judgments. Interestingly, this pattern would occur despite creativity and beauty being driven partly by the same antecedent factors of novelty and typicality, and would be caused by the opposing directionality of the typicality effect on the two constructs. What we found was that the two constructs only correlated minimally and not consistently in the same direction (Experiment 1 showed a small negative and significant correlation, and Experiment 2 showed a small positive but insignificant correlation). A likely explanation for the varying correlational directionality is that the two constructs are effectively unrelated, and repeated measures in slightly different experimental designs will then necessarily display varying directionality with a tendency towards zero in larger samples. But it could also be argued that these findings seem to suggest that this may be a case of object-attribute interactivity (Osgood, Suci, \& Tannenbaum, 1957), where the relation between consumer perceived creativity and beauty behave differently (i.e., that they mean different things in consumer's minds), depending on the product categories chosen, given that different object categories (lamps, watches) were used across the experiments. However, we had no apriori reason to expect that specifically designer lamps would display a small significant negative relation between judged creativity and beauty as opposed to wrist watches, and therefore we maintain that the most likely explanation is that the true correlation between beauty and creativity is minimal. 
The subjectivity of the consumer perception measures used here is underscored by the fact that instruction ordering effects were found in experiment 1 (i.e., it did matter somewhat whether creativity was rated first, or subsequently to beauty or WtP, with a significant drop in agreement if creativity was not rated first). This may mean that different raters may have used different definitions of the concept of creativity (cf. Rossiter, 2002), as observed in earlier research on how people judge creativity (Koslow, Sasser, \& Riordan, 2003). However, in experiment 2, no ordering effects were identified in a group of females rating female watches. Given the almost identical experimental setup in experiment 1 and 2 (apart from the rated objects) it seems possible that this difference is caused by different product domains having distinct optimal subjectively sought levels of beauty and creativity when assessing object value, since method variance was otherwise low. Perhaps wrist watches and designer lamps do differ in subtle ways as to how consumers respond to their levels of beauty and creativity.

The most significant finding here was the consistent finding that consumer perception of product creativity predicted consumers’ willingness to pay for the product. This was found consistently across experiments, where both creativity and beauty predicted consumer willingness to pay, explaining different parts of the variance. Including list price in the regression did not alter the results significantly. Perceived product creativity predicted consumer willingness to pay both across (Experiment 1) and within (Experiment 2) consumer groups. Furthermore, no evidence of interaction effects between consumer perceived creativity and beauty on their relation to willingness to pay was found, indicating again that these are two distinct constructs with distinct effects. The finding that perceived product creativity consistently predicted consumer willingness to pay for products equivalent in function is particularly interesting for domains where there is a de-emphasis on functional or use value, such as advertising, products consumed primarily for their experiential value, design objects etc. 
The present set of experiments demonstrated that judged creativity and perceived beauty contributed independently to willingness to pay. This indicates that it is necessary to treat the two concepts separately in models of product evaluation in consumer psychology, rather than subsume them under one aesthetic dimension.

Our findings are especially relevant to classes of products that either are bought predominantly for their aesthetic appeal, or are assumed to be equivalent in function. Consumers do not question the assumption that lamps provide light and therefore are willing to pay for design (Experiment 1). Likewise, consumers assume that wrist watches tick with the same pace, and that they do not have to evaluate timing quality; therefore they can consider non-functional qualities like beauty and creativity (Experiment 2).

While single-item perceived consumer creativity and beauty for the present purposes proved reliable measures with predictive validity, a possible limitation to this study is the usage of singleitem responses to the measure of consumer's willingness to pay. Further research should explore whether the findings may generalize to other estimates of consumer behavior, such as willingness to pay rating scales, or real-life purchase decision paradigms, where the objects in question may actually be purchased/won by the study participants. Such an experimental setup may be used to prove the validity of the present approaches to real-life purchase contexts. Furthermore, it should be stressed, that the purposes in the present study was the examination of consumer's own subjective perceived notion of creativity. This particular purpose led to the methodological choice of using single-item measures, but future studies should be aware that if the purpose is to measure nonsubjective levels of object creativity, or measure creativity in domains with a heavy emphasis on object usability or functionality, then it may be advisable to consider multi-item creativity scales separating the construct into distinct subcomponents if appropriate components and weights can be identified for the domain in question. Our findings have deep implications for applications in 
product design and market research. As the simplistic assumption is wrong that either creativity or beauty alone determine willingness to pay, designers have the obligation to consider both creativity and beauty of the product. This obligation, however, can be turned into an opportunity because creativity and beauty are only weakly related, and they explain different parts of the variance for willingness-to-pay. Therefore, they can try to maximize both dimensions independently. The implications of the present findings may be illustrated through contrast with the findings by Hekkert et al. (2003). They found that typicality and novelty jointly predicted aesthetic preference (beauty), but that typicality and novelty suppressed each other's effects. Hekkert et al. argued that the results proved to be empirical evidence for the MAYA principle coined by Raymond Loewy. The MAYA principle is an acronym for 'Most Advanced, Yet Acceptable', whereby the designer should strike a balance between the novelty and typicality of the design. The present findings extend these observations, by focusing on consumer's willingness to pay. For willingness to pay, the present findings implicate that aesthetic appreciation is but one predictor - another distinct and equally important predictor being consumer-perceived creativity. Given that novelty is positively related to both of the mediating variables of beauty and creativity, it would seem to implicate that for WTP the MAYA principle may be skewed towards more advanced (novel) products with perhaps less focus on acceptable (typical) products. In applying the MAYA principle, designers should thus keep in mind that striking a proper balance may well depend on which outcome variable they are looking to enhance in their designs (i.e., aesthetic appreciation vs. consumer willingness to pay for the product).

The main insight of this study is that both creativity and beauty contribute to willingness to pay measures, suggesting the strong need for the development of distinct theoretical models of perceived creativity and perceived beauty in consumer research and distinct practical approaches to 
design that maximize the joint contribution of creativity and beauty to the willingness to buy and to pay for a product. 
Reference List

Alpeson P. 2003. Creativity in art, in The Oxford Handbook of Aesthetics J. Levinson (Ed.) New York: Oxford University Press.

Amabile T. 1982. Social psychology of creativity: A consensual assessment technique. Journal of Personality and Social Psychology, 43: 997-1013.

Bell, J. A. (1992). Creativity, TV commercial popularity, and advertising expenditures. International Journal of Advertising, 11(2), 165-173

Besemer S. \& Treffinger D. J. 1981. Analysis of creative products: Review and synthesis. Journal of Creative Behavior, 15: 158-178.

Bianchi M. 1998. The taste for novelty and novel tastes: The role of human agency in consumption, in The active consumer: Novelty and surprise in consumer choice, M. Bianchi (Ed.). London: Routledge: 6486.

Blijlevens, J., Carbon, C., Mugge, R., \& Schoormans, J. P. L. (2012). Aesthetic appraisal of product designs: Independent effects of typicality and arousal. British Journal of Psychology, 103(1), 44-57.

Bloch P. Brunel F. F. \& Arnold, T. J. 2003. Individual differences in the centrality of visual product aesthetics: Concept and measurement. Journal of Consumer Research, 29: 551-565.

Bruce M. \& Whitehead M. 1988. Putting design into the picture: The role of product design in consumer purchase behavior. Journal of the Market Research Society, 30: 147-162.

Caroff X. \& Besancon M. 2008. Variability of creativity judgments. Learning and individual differences, 18: 367-371. 
Cho H. \& Schwarz N. 2006. If I don't understand it, it must be new: Processing fluency and perceived product innovativeness. Advances in Consumer Research, 33: 319-320.

Christiaans H. H. C. M. 2002. Creativity as a design criterion. Creativity Research Journal, 14: 4154.

Dahlen, M., Törn, F., \& Rosengren, S. (2008). Advertising creativity matters. Journal of Advertising Research 48(3), 392-403.

Eisend, M. 2009. A Meta-analysis of Humor in Advertising. Journal of the Academy of Marketing Science 37: 191-203.

Goldschmidt, G., \& Tatsa, D. 2005. How good are good ideas? Correlates of design creativity. Design Studies, 26: 593-611.

Hagtvedt H., Hagtvedt R., \& Patrick V. M. 2008. The perception and evaluation of visual art. Empirical studies of the arts, 26: 197-218.

Hasselzahl M. 2008. Aesthetics in interactive products: Correlates and consequences of beauty, in Product experience, H.N.J.Schifferstein \& P. Hekkert (Eds.). Oxford: Elsevier.

Hassenzahl, M. (2004). The interplay of beauty, goodness, and usability in interactive products. Human-Computer Interaction, 19(4), 319-349.

Hekkert P. \& Leder H. (2008). Product aesthetics, in Product experience, in H. N. J.Schifferstein \& P. Hekkert (Eds.). Oxford: Elsevier.

Hekkert, P., Snelders, D. \& van Wieringen, P. C. W. (2003). Most advanced, yet acceptable: Typicality and novelty as joint predictors of aesthetic preference in industrial design. British Journal of Psychology, 94, 111-124. 
Hirschman E. C. 1980. Innovativeness, novelty seeking, and consumer creativity. Journal of Consumer Research, 7: 283-295.

Holbrook M. B. 1980. Some preliminary notes on research in consumer esthetics, in Advances in Consumer Research, Vol. 7, J.C.Olson (Ed.). Ann Arbor: Association for Consumer Research: 104-108.

Holbrook M. B. \& Hirschman E. C. 1982. Experiential Aspects of Consumption: Consumer Fantasies, Feelings, and Fun. Journal of Consumer Research, 9: 132-140.

Horn D. \& Salvendy G. 2006. Consumer-based assessment of product creativity: a review and reappraisal. Human Factors and Ergonomics in Manufactoring, 16: 155-175.

Horn D. \& Salvendy G. 2009. Measuring consumer perception of product creativity: Impact on satisfaction and purchasability. Human Factors and Ergonomics in Manufactoring, 19: 223-240.

Janiszewski C. 1993. Preattentive mere exposure effects. Journal of Consumer Research, 20: 376392.

Keller K. L. (2008). Strategic Brand Management. Building, Measuring, and Managing Brand Equity (3rd ed.). Upper Saddle River, New Jersey: Pearson Prentice Hall.

Koslow, S., Sasser, S. \& Riordan, E. A. (2003). What Is Creative to Whom and Why? Perceptions in Advertising Agencies. Journal of Advertising Research, 43: 96-110.

Kozbelt A. 2004. Originality and technical skill as components of artistic quality. Empirical studies of the arts, 22: 157-170.

Mayer R. E. 1999. Fifty years of creativity research, in Handbook of creativity, R. J. Sternberg (Ed.). Cambridge, UK: Cambridge University Press: 449-460.

Moore D. J. \& Harris, W. D. 1996. Affect Intensity and the Consumer's Attitude toward High Impact Emotional Advertising Appeals. Journal of Advertising , 25: 37-50. 
O'Quin K. \& Besemer S. 1989. The development, reliability, and validity of the revised creative product semantic scale. Creativity Research Journal, 2: 267-278.

O’Quin K. \& Besemer S. P. 2006. Using the Creative Product Semantic Scale as a metric for resultsoriented business. Creativity and Innovation Management, 15(1): 34-44.

O’Quin, K. \& Besemer, S.P. 2011. Creative products. Encyclopedia of Creativity. Ed. Mark A. Runco and Steven R. Pritzker. 2nd ed. Vol. 1. London: Academic Press, 273-281.

Osgood, C.E., Suci, G., \& Tannenbaum, P. 1957. The measurement of meaning. Urbana, IL: University of Illinois Press.

Purcell A. T. 1984. The aesthetic experience and mundane reality, in Cognitive processes in the perception of art, W.R.Crozier \& A. J. Chapman (Eds.). Lisse, The Netherlands: Elsevier.

Reber R., Schwarz N. \& Winkielman P. 2004. Processing Fluency and Aesthetic Pleasure: Is Beauty in the Perceiver's Processing Experience? Personality and Social Psychology Review, 8: 364-382.

Reber R., Winkielman P. \& Schwarz N. 1998. Effects of perceptual fluency on affective judgments. Psychological Science, 9: 45-48.

Rogers E. M. 1976. New product adoption and diffusion. Journal of Consumer Research, 2: 290301.

Rossiter J. R. 2002. The C-OAR-SE procedure for scale development in marketing. International Journal of Research in Marketing, 19: 305-335.

Sasser S. L., \& Koslow, S. (2008). Desperately seeking advertising creativity. Journal of Advertising, 37 (4), 5-19.

Schneider W., Eschman A. \& Zuccolotto A. 2002. E-Prime user's guide. Pittsburgh: Psychology Software Tools, Inc. 
Shrout P. E. \& Fleiss J. L. 1979. Intraclass Correlations: Uses in Assessing Rater Reliability. Psychological Bulletin 86 (2): 420-428.

Shrout P. E. 1998. Measurement reliability and agreement in psychiatry. Statistical Methods in Medical Research, 7: 301-317.

Simonson I. \& Nowles S. M. 2000. The role of explanations and need for uniqueness in consumer decision making: Unconventional choices based on reasons. Journal of Consumer Research, 27: 49-68.

Smith, R. E., Chen, J, \& Yang, X. 2008. The impact of advertising creativity on the hierarchy-ofeffects. Journal of Advertising, 37: 47-61.

Veryzer R. W. \& Hutchinson J. W. 1998. The influence of unity and prototypicality on aesthetic responses to new product designs. Journal of Consumer Research, 24: 374-394.

West, D. C., Kover, A. J., \& Caruana, A.(2008). Practitioner and customer views of advertising creativity: Same concept, different meaning?” Journal of Advertising, 37 (4), 35-45.

Winkielman P. \& Cacioppo J. T. 2001. Mind at ease puts a smile on the face: Psychophysiological evidence that processing facilitation leads to positive affect. Journal of Personality \& Social Psychology, 81: 989-1000.

Yusuf, S. 2009. From creativity to innovation. Technology in Society, 31: 1-8.

Zangwill N. 2003. Beauty, in The Oxford Handbook of Aesthetics, J. Levinson (Ed.). New York: Oxford University Press. 
Author notes 
Table 1. Intraclass correlation coefficients and reliability correlations across groups in Experiment 1.

\begin{tabular}{lccc}
\hline & ICC & B after W & B after C \\
\hline Beauty rated first & .883 & $.61^{* *}$ & $.64^{* *}$ \\
Beauty rated after W & .785 & & $.84^{* *}$ \\
Beauty rated after C & .726 & & \\
\hline & & W after B & W after C \\
\hline $\begin{array}{l}\text { Willingness-to-Pay rated } \\
\text { first }\end{array}$ & .708 & $.37^{*}$ & $.65^{* *}$ \\
$\begin{array}{l}\text { Willingness-to-Pay rated } \\
\text { after B } \\
\text { Willingness-to-Pay rated }\end{array}$ & .820 & & .31 \\
after C & .697 & & \\
\end{tabular}

C after W C after B

Creativity rated first .917

$.91^{* *}$

$.85^{* *}$

Creativity rated after $\mathrm{W}$

.930

$.88^{* *}$

Creativity rated after B

.805

Correlation between mean evaluations of beauty (B), creativity (C), and Willingness-to-Pay (W) by instruction order (ratings done first, or subsequent to the other measures).

**. Correlation significant a the 0.01 level (2-tailed)

*. Correlation significant at the 0.05 level (2-tailed) 
Table 2. Average willingness-to-pay for the ten least/most beautiful and ten least/most creative products in both experiments.

\begin{tabular}{lllll}
\hline & & \multicolumn{2}{c}{ Average willingness to pay } & \\
& Ten products & Ten products & Ten products & Ten products \\
& judged as least & judged as most & judged as least & judged as most \\
& beautiful & beautiful & creative & creative \\
& & & & \\
\hline Experiment 1 & USD 277.2 & USD 336.7 & USD 282.9 & USD 312.5 \\
(lamps) & & & & \\
Experiment 2 & USD 88.9 & USD 130.4 & USD 86.5 & USD 137.6 \\
(watches) & & & & \\
\hline
\end{tabular}




\section{FOOTNOTES}

${ }^{i}$ All reported currencies have been converted to USD for ease of comparison.

${ }^{\text {ii }}$ Additionally we ran a few male subjects rating male watches only $(n=20)$. We excluded these subjects from the present study due to a less than acceptable ICC $(2,20)=.557$ for willingness to pay (a 'fair' level of agreement), probably due to the low N. For males ICC for creativity was substantial ICC $(2,20)=.900$ and for beauty it was moderate ICC $(2,20)=.635$. Moreover, the regression analyses yielded the same findings (both creativity and beauty independently and significantly predicted willingness to pay) if we included male participants rating male watches. 